\title{
14 The multiple disguises of spiders
}

\author{
Marc Théry, Teresita C. Insausti, Jérémy Defrize and Jérôme Casas
}

\subsection{Introduction}

This chapter aims at a broad exploration of the literature pertinent to the subject of spider camouflage, from web colour and decorations, body colour to movement. It is an extended and updated version of a previous paper (Théry \& Casas 2009). Several functions have been assigned to spider web decorations, the most extensively studied being visually related, like camouflage from predator and/or prey, prey attraction and signalling to animals that are likely to damage the web (Herberstein et al. 2000; Bruce 2006). The function of these structures is highly controversial, as also are other visual aspects of spider ecology, like the appearance of spiders themselves. Moreover, a few spider species have the ability to change their body coloration, a peculiarity that has been suggested to improve camouflage or to constitute a form of aggressive mimicry (Oxford $\&$ Gillespie 1998). Are such visual appearances used to lure prey, deter predators or hide from predators or prey?

In this study, we carry out a critical review of the abundant literature on spider and web appearance, predominantly focussing on the potentiality of camouflage and mimicry. For this reason, we will not explore non-visual aspects like spider olfactory and tactile mimicry or several other hypothetical functions of web decorations. When possible, we will highlight studies considering the visual sensitivities of prey and predators, and the transmission properties of visual signals through the environment. In addition to reviewing possible cases of camouflage, we will report on the nature of pigments used for colour change, and evoke physiological and ecological hypotheses for colour change. We will also discuss one neglected hypothesis, protection against UV photodamage, by making a comparison of the pigmentation of two crab spider species, one being cryptic and the other non-cryptic.

\subsection{Web design, colour and visual environment}

Spiders specialising on small prey which are characterised by highly evolved visual systems and flight behaviour face the problem of avoiding detection, and studies of 
insect vision and flight show that it is surprising that webs capture any prey at all (Craig 1986). However, the sophisticated design of webs enhances prey capture by making the web difficult to detect. Low-frequency oscillations of webs with low fibre density designed to resist only low impact, like those of Theridiosoma globosum, are specialised to capture small slow-flying prey by fluctuating with the low airflow the web surface in and out of an approaching prey's range of visual resolution (Craig 1986). In contrast, high impact webs such as those of Mangora pia are built with denser and more visible silk and do not oscillate because changes in light intensity across the web surface would cause the web to appear as a visual flag (Craig 1986). As an alternative to dynamic distortion, some spiders in the genera Theridiosoma and Epeirotypus use static distortion by pulling the web centre approximately $3-5 \mathrm{~cm}$ with a fibre attached to surrounding vegetation. They build a cone web which escapes the range of visual resolution of potential prey, because when prey are flying at the base of the cone web they are not able to see the web centre or area of highest fibre density (Craig 1986). The centre thread is released and the web projected towards a prey when it comes within the reach of the distorted web.

Web visibility is also greatly affected by the light environment. Background pattern has little influence on web visibility in dim- light environments, whereas small background patterns close to the web disrupt the web outline in bright-light environments (Craig 1990). The changing patterns of shade and sunflecks on the web also make the orb difficult to detect (Craig \& Freeman 1991). In laboratory experiments, Drosophila melanogaster has difficulty in seeing webs suspended close to backgrounds of high spatial frequency in bright light, and are unable to see and avoid webs characterised by low reflectivity (Craig 1990).

Particular silks affect attraction of prey. Webs of Araneidae and Tetragnathidae, which include viscid droplets of glycoprotein, have a sparkling appearance that functions to attract prey to the web area although at short range they make webs more visible (Craig \& Freeman 1991). Viscid silk increases the probability of prey interception of both diurnal and nocturnal species, although this is only true in the brightest habitats for nocturnal species (Craig \& Freeman 1991). However, using more sticky viscid silk also makes webs more visible to prey. Consequently, nocturnal spiders or those living in dim habitats are able to enhance web stickiness by using highly visible viscid silk, whereas species foraging in bright habitats are constrained to build less visible and consequently less sticky orbs that are less efficient at retaining large prey (Craig 1988). Nephila clavipes, the golden orb weaver, is unique among spiders studied to date for its ability to adjust web reflectance to local light and to produce pigments that enhance web visibility by increasing light reflected by their silk (Craig et al. 1996). It produces yellow silk which exploits the visual and behavioural systems of insects in the different light environments where it forages. In environments with high light intensity or in forest gaps, $N$. clavipes produces yellow silk that attracts bees. In contrast, they do not produce pigments in dim sites where silk colours are difficult to see, probably to achieve energetic savings. Similarly, Argiope aetherea and A. keyserlingi build more and longer decorations under dim light than bright light, probably to increase the attractive signal for approaching prey or to advertise the web to oncoming birds (Elgar et al. 1996; Herberstein \& Fleisch 2003). 


\subsection{Web decorations}

Web decorations are conspicuous silk structures spun in webs by females of some species of orb-web spiders. While the most-studied decorations are entirely made of silk, some spider species combine silk with organic items such as egg sacs and debris. Because empirical studies have shown that decorations made of different materials function quite differently, we will consider them separately.

\subsubsection{Silk decorations}

Silk decorations were originally called stabilimenta because they were thought to help the web to stabilise. Several other functions have been advanced, including camouflage, prey attraction, increase in apparent female size, signalling to species likely to damage webs, thermoregulation, stress, regulation of excess silk, balance of water metabolism and male attraction (Eisner \& Nowicki 1983; Herberstein et al. 2000; Starks 2002; Bruce 2006; Walter et al. 2008, 2009). To solve this controversy, one suggestion of Herberstein et al. (2000) was to identify phylogenetic clusters of web decorations, because within these clusters decorations may have similar functions as a result of common ancestry. This hypothesis is not supported in the most studied cluster, the 'argiopine'. If we consider the most extensively studied hypothetic functions, the foraging and the antipredatory functions, opposite results have been found in the genus Argiope. Most studies have found support for improved foraging success of decorated webs, but others found opposite results (review by Théry \& Casas 2009). Even more surprisingly, contradictory results have been found in the same species, Argiope aurantia (Tso 1998 supporting the improved foraging function, Blackledge \& Wenzel 1999 not). Similarly, testing the antipredatory hypothesis in Argiope led to diverging conclusions: some studies support this hypothesis but others do not (review by Théry \& Casas 2009). Therefore, the hypothesis that similar decoration patterns, like the bright white silk bands of decorations frequently spun by spiders of the 'argiopine' cluster, may be convergent in form and function (Herberstein et al. 2000) cannot be supported.

The general absence of decorations in nocturnal spiders supports a visually mediated function. One common trend is that, when the prey attraction function is supported, the anti-predatory function is not, or the reverse (review by Théry \& Casas 2009). The only studies simultaneously validating both functions are very speculative and provide no direct evidence for support of both hypotheses (Herberstein \& Fleisch 2003; Rao et al. 2009). A recent study of silk tuft decorations in Gasteracantha cranciformis supports neither the prey attraction nor the web advertisement hypothesis, and suggests an aposematic function (Gawryszewski \& Motta 2008). Using silk decorations may constitute a conditional strategy which performs multiple functions both within and across populations (and species) depending on (i) spider developmental stages, (ii) their energetic state or (iii) environmental factors such as the relative proportions of predator types, the population-specific prey differences in decoration susceptibility, the presence 
of bird species likely to damage webs or differences in temperature or ambient light (review by Théry \& Casas 2009).

Evidence for camouflage has been found when decorations conceal the spider from predators or change its apparent shape, although earlier studies did not perform field or laboratory experiment and were more descriptive and speculative. Blackledge \& Wenzel (2000) argued that decorations are cryptic to insects because their reflectance spectra are flat, but they do not provide any data to test this assumption. On the contrary, Craig \& Bernard (1990) showed in a closely related Argiope species that both decorations and spiders reflect UV wavelengths that act as a visual signal to attract prey. Li et al. (2004) also showed that the discoid decoration spun by juvenile Argiope versicolor is a prey attractant under white light containing UV. Spiders that decorate their webs at higher frequency not only grow faster, but also take higher predation risks (Li 2005). Numerous recent studies indeed showed that silk decorations induce significant cost to spiders by attracting specialised spider-eating predators, like praying mantids, Portia jumping spiders or wasps (e.g. Bruce et al. 2001; Seah \& Li 2001; Cheng \& Tso 2007). Evidence for prey deception has been suggested when decorations attract pollinating insects by reflecting UV light in patterns similar to UV markers on flowers. Similarly, UV patches created by web decorations may resemble gaps in vegetation that elicit flight behaviour in many insects (Craig \& Bernard 1990). By reconstructing a molecular phylogeny of Asian Argiope spiders and by conducting field experiments on the luring effectiveness of decorations forms, Cheng et al. (2010) showed that linear decorations are ancestral and cruciate decorations derived, the later being more attractive to insect prey. Their results suggest that the innate preference of pollinating insects for particular bilateral or radial symmetrical patterns might be driving the arrangement pattern of web decorations. However, until recently, the visually mediated functions of web decorations could not be properly tested with regard to the visual sensitivities of prey or predators, as well as the spectral characteristics of the visual background and ambient light.

Bruce et al. (2005) were the first to evaluate the visibility of silk decorations to both prey and predators by considering visual systems, background colour and the ambient light spectrum. Both achromatic and chromatic contrasts were calculated to estimate conspicuousness of the spiders against green vegetation background or against their decorations, at long and short distances, respectively. It was found that decorations were highly conspicuous to both predators and prey at long and short distance. However, the discoid decoration of Argiope mascordi could provide some camouflage for spiders seen by Hymenoptera, either prey or predator.

A second study has used visual system modelling to evaluate the conspicuousness of silk decorations to potential prey and predators (Rao et al. 2009). In the orb-web spider Argiope radon, it was found that spider abdomens generate pronounced chromatic and achromatic contrasts on web decorations when seen by Hymenoptera, and even stronger contrasts when seen by birds. Because in both visual systems decorations are more conspicuous than spiders, the function of decorations could be to confuse the attack of avian or insect predators. Recently, Blamires et al. (2008) have shown that spiders attract insects with decorations by exploiting visual sensory biases of prey sensitivities in the 
blue and UV light. However, it is still unknown whether UV, blue light or both are the most important cue.

Another approach to test the anti-predator function of silk decorations has been used by Nakata (2008) who simulated the approach of a flying insect predator with a vibrating tuning fork, and examined whether Eriophora sagana spiders modified the total thread length and the area of decorations of their subsequent web. It was found that spiders exposed to the simulated predator did not increase their thread length but attached more decorations to their new web, contrary to control spiders. These experiments support the anti-predator function of silk decorations. Nakata (2009) used the same approach with Cyclosa argenteoalba, but this time also experimentally tested the influence of prey availability on web design. His results confirmed the anti-predator function of decorations, and also showed that spiders increase their thread length but not the area of decorations when more prey is available. Overall, this shows that web decoration does not necessarily involve a trade-off between deterring predators and being avoided by prey.

\subsubsection{Detritus decorations}

Detritus decorations are generally thought to function as camouflage for the spider (Eberhard 2003; Chou et al. 2005; Gonzaga \& Vasconcellos-Neto 2005). Detritus decorations added to the webs of two Cyclosa species could reduce the intensity of predation, possibly by disrupting the spider's outline (Gonzaga \& Vasconcellos-Neto 2005). Egg sac and silk decorations were also suspected to be used for camouflage by Allocyclosa bifurca spiders at the hub, although no rigorous behavioural test was conducted to support this interpretation (Eberhard 2003). However, the odour of yeast growing on prey remains or decaying plant material incorporated above the orb web may also be used to attract insect prey (Tietjen et al. 1987; Bjorkman-Chiswell et al. 2004).

Physiological models of vision were used to calculate chromatic and achromatic contrasts of Cyclosa confusa spiders and their prey carcass decorations as they are viewed by their hymenopteran predator (Chou et al. 2005). However, the authors compare both chromatic and achromatic contrasts with a minimal value of discrimination computed by Théry \& Casas (2002) for chromatic contrast detection by hymenopteran insects, a value which is not known for achromatic contrast detection (Théry \& Casas 2002; Bruce et al. 2005; Théry et al. 2005). Filming prey interception and predation events showed that carcass decorations do not attract insects and even generate a foraging cost, but that predators redirect their attacks towards decorations, which allows spiders to escape predation (Chou et al. 2005). The function of Cyclosa confusa decorations is neither related to camouflage from predator or to prey attraction, but is apparently to confuse the attacking predator.

Tan \& Li (2009) also used physiological models of vision to evaluate the camouflage efficiency of Cyclosa mulmeinensis spiders on their egg-sac and prey-remain decorations as they are seen by an insectivorous avian predator and hymenopteran prey or predator. Direct tests performed in the field showed that decorated webs intercept more insects, probably because spiders could not be discriminated from their decorations by prey 
using chromatic contrast at short distance. An alternative explanation is that, even if spiders are conspicuous to prey viewing them on their decorations using achromatic contrast at long distance, yeast may be growing on decorations an attract prey by olfaction, as shown by Tietjen et al. (1987). On the other hand, decorations seem to camouflage spiders against bird predators but not against wasps. Contrasting with the results obtained in other Cyclosa species (e.g. Chou et al. 2005), detritus decorations of $C$. mulmeinensis thus appear to constitute a trade-off between improving foraging success and reducing predation risk. Tseng \& Tso (2009) also studied the camouflage efficiency of $C$. mulmeinensis on their egg-sac and prey-remain decorations as they are seen by their wasp predators. Predators' responses to spiders on webs were recorded on the field. As in the study of Tan \& $\mathrm{Li}$ (2009), it was found that spiders and decorations were conspicuous to wasp predators, and that webs with more decorations suffered higher predation. However, because decorations resemble spiders in size and colour, they distracted predators and were frequently attacked, enhancing spider survival. The trade-off between improved foraging success and reduced predation may explain the variable incidence and polymorphism of web decorations in this species.

Tan et al. (2010) tested the prey attraction and the anti-predatory hypotheses in Cyclosa ginnaga, a species which decorates its web with plant material and/or silk. They found that silk decorations were used as luring signals that attract prey visually, and that plant detritus and the silvery body coloration may also be attractive to insect prey. However, they could not conclude on the effectiveness of decorations to provide protection from predators because no instance of predation was observed for any web.

\subsection{Spider coloration: generalities}

Spider coloration has been reviewed in Oxford \& Gillespie (1998) and their excellent overview is still up to date a decade later. Coloration serves multiple purposes, from crypsis and aposematism to sexual selection, and its underlying physiological processes are as numerous. Since then, the biochemical foundation of coloration in spiders has seen little progress compared with the sensory physiology of colour perception. The genetical and evolutionary work on the colour polymorphism is reviewed in Oxford \& Gillespie (2001) for the happy-face spider (Theridion grallator) and in Oxford (2005) for the candy-stripe spider (Enoplognatha ovata). The evolutionary forces for the persistence of colour polymorphism in spiders remain generally elusive. In contrast, two areas have attracted most of the attention, the colour-changing properties of crab spiders and the striped and bright body coloration in web spiders. The studies conducted on those two aspects are similar in spirit to the work on the web decorations, often produced by the same species. In a recent study, Bush et al. (2008) carried out ingenious experiments on the wasp spider Argiope bruennichi by masking the spiders behind a leaf or painting their otherwise brightly coloured body, as did Tso et al. (2006) and Chuang et al. (2007, 2008). The marked decrease in prey capture in all cases is strong proof of the attractive nature of the brightly coloured body, and is consistent with the work of Chuang et al. $(2007,2008)$ and Tso et al. (2007) on brightly coloured nocturnal spiders. Quite different 


\subsection{Spider coloration: pigments responsible for colour change}

The colour-changing crab spiders of the family Thomisidae, in particular Misumena vatia and Thomisus onustus, have been studied since 1891 (Heckel 1891) with respect to pigmentation. Misumena vatia represents one of most studied spiders, with a monograph devoted exclusively to its life history (Morse 2007). This spider is unusual as it is able to change reversibly, with a time delay of a few days, from white to yellow and back. Colour change is induced by background colour and colour of prey (Théry 2007 and references therein). The background matching ability of these spiders is at times astonishing, below the discrimination ability of bees for example (see Figure 14.1; Chittka 2001; Théry \& Casas 2002; Théry et al. 2005). Both food and light quality have been found to increase the range of colour change, but the variability in the response level was very high, with many individuals remaining white despite strong yellow stimuli (Théry 2007). This form of crypsis has been interpreted as being potentially both a defensive (hiding from predators) and aggressive (hiding from prey) one. Bees and other flower-visiting insects are indeed common prey. Predation events by vertebrate predators, however, have never been observed (Morse 2007), whereas predation by mud-dauber and spider wasps has often been observed. The impact of these invertebrate predators on spider populations is nonetheless unknown. Aggressive crypsis might therefore be the only type of crypsis present. Such impressive camouflage begets many questions about its proximate and ultimate mechanisms. In the following, we first report on the nature of pigments. We then move on to the physiological and ecological hypotheses for colour change, and close our discussion with one neglected hypothesis, the protection against UV photodamage, by making a comparison with another, non-cryptic, crab spider.

Older studies assumed that the yellow colour of $M$. vatia was due to carotenoids (Millot 1926), but ommochromes were later found to be the pigments responsible for this colour (Seligy 1972). Ommochrome pigments are a class of pigments, widespread in insects and other arthropods, which constitute the main chromogenic class in the pathway from tryptophan and range from gold through red, purple and violet, up to brown and black. The reduced form is usually red and the oxidised form usually yellow. The characteristic properties of ommochromes (redox behaviour, absorption of UV and 

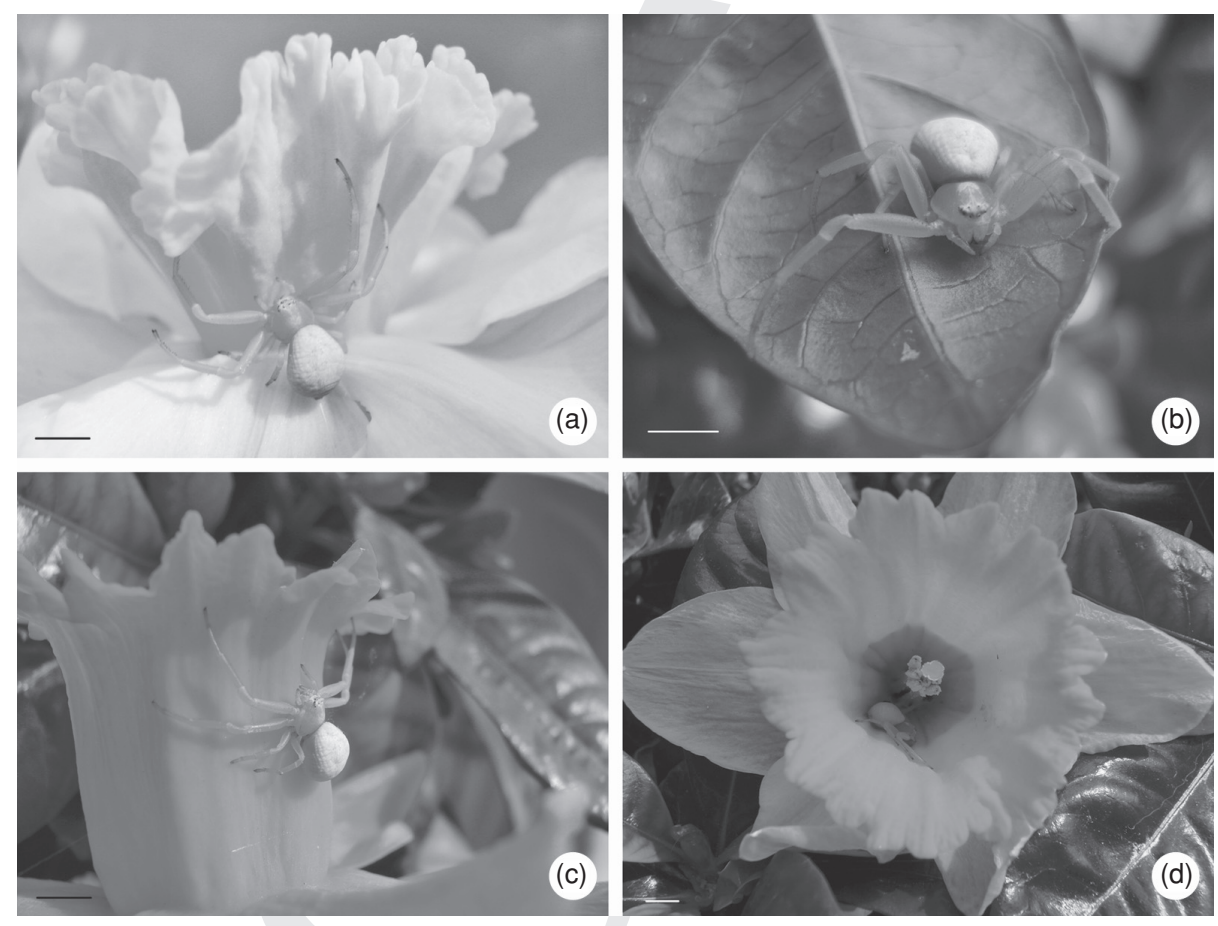

Figure 14.1 Importance of translucent teguments and white reflectance from guanine in background matching by the crab spider Misumena vatia. The same pale yellow female is represented in the four pictures, taken at an interval of a few minutes. Depending on the exact location of the spider on a plant, $(a, b)$ the different hues between the cephalothorax and legs, and the opisthosoma, may make the animal more difficult to detect, (c) the green coloration of leaves may shine through the translucent legs and (d) the strong yellow hue within the corolla can be reflected by the guanine, leading to a high degree of camouflage. Scale bar $=6 \mathrm{~mm}$. See plate section for colour version.

visible light, and low solubility) enable them not only to act as authentic functional pigments (eyes, integument), but also as an electron-accepting or -donating system and as metabolic end products (Needham 1974). Ommochromes, principally xanthommatin, are widely distributed in arthropods as screening pigments in the accessory cells of the eyes and are also present in the retinula cells (Linzen 1974). Ommochrome pigments are little known in general and their catabolism is very poorly understood, except for the latest work by Insausti \& Casas (2009). The biochemical basis for the reversible colour change is not understood. One remains simply dismayed at the disappearance of solid biochemical work on a complete class of pigment after the 1970s and 1980s, just before the advent and rise of molecular biology (Linzen 1974; Needham 1974; Fuzeau-Braesch 1985; Kayser 1985). Luckily, the situation is somewhat better in terms of the ultimate reasons for the colour change.

The functions of ommochromes are diverse and several complementary and nonexclusive hypotheses have been suggested for their common occurrence (reviewed in Insausti \& Casas 2008). The first hypothesis states that the ommochrome pathway is 
the main pathway for avoiding excess accumulation of the highly toxic tryptophan. Supporting this hypothesis is the observation that ommochrome formation is strongly correlated with the massive breakdown of proteins at the onset of metamorphosis. This is the oldest and most popular view for the function of ommochromes. This conclusion is however invalidated for M. vatia by Insausti \& Casas (2008) on the basis of the red stripes in white spiders. The absence of a change of colour from white to yellow cannot be due to a lack of precursors or enzymes (as found in the white eyes clone of D. melanogaster: Mackenzie et al. 2000), as these spiders have both. Tryptophan might already be neutralised as ommochrome precursor in those granules containing most likely kynurenine.

The second hypothesis states that main raison d'être of ommochromes is signalling, mimicry and crypsis. This is the hypothesis supported by most of the community working on colour-changing insects such as stick insects and mantids (Fuzeau-Braesch 1985), including Mantis religiosa, Sphodromantis viridis and Locusta migratoria (Vuillaume 1968), and spiders (review in Théry \& Casas 2009). In order to test this hypothesis, we need to assess the fitness value of the camouflage and the fitness gain from a change of colour. It can be based on the measurement of some fitness-related trait, such as increased fecundity, survival or simply higher prey capture rate as a function of the degree of flower colour matching. This is a main piece of supporting evidence that is often missing and the latest results obtained by Brechbühl et al. (2010), showing that colour-matched crab spiders do not have a higher prey encounter rate or capture success than conspicuous ones, do not support this hypothesis. We also need to assess the likelihood of the 'nearly perfect' matching of spiders to their flowers referred to earlier. This in turn, requires the sampling of the colour of all flowers in the neighbourhood of the one chosen by a spider. The latest results obtained from systematic field survey indicate that the matching of spider and flower colours is not different from a random assortment (Defrize et al. 2010). Thus, supporting evidence for the second hypothesis is scant.

The third hypothesis is based on the observation that the major function of ommochrome in eyes is the protection of photosensitive visual cells against excessive scattered light, and also protection against photodestruction by intense UV light (Langer 1975; Stavenga 1989). Ommochromes participate in the antioxidative system in invertebrate photoreceptors, as melanin in the eyes of vertebrates (Dontsov et al. 1984; Ostrovsky et al. 1987; Sakina et al. 1987; Dontsov 1999). The ommochromes are also effective inhibitors of free-radical-induced lipid peroxidation. Lipid peroxidation is also produced by photooxidation and is indicative of photoreceptor damage, expressed in the retina by the deterioration of photoreceptor membranes (Ostrovsky \& Fedorovich 1994). The hypothesis that ommochromes in the tegument have a similar function deserves therefore much more attention for the following reasons. First, ommochrome precursors could be sufficient as screening pigments, as in the group of chartreuse mutants of Apis mellifica (Linzen 1974). Indeed, the mutant group accumulates the yellow-tinted but still translucent 3-OH-kynurenine in a granular form in the pigment cells of the compound eyes. That pigment precursor therefore assumes a pigment function (Linzen 1974). The intensity of the yellow hue of spiders, due to the mix between 3-OH-kynurenine and ommochromes, might reflect the amount of screening against radiation. Second, M. vatia 


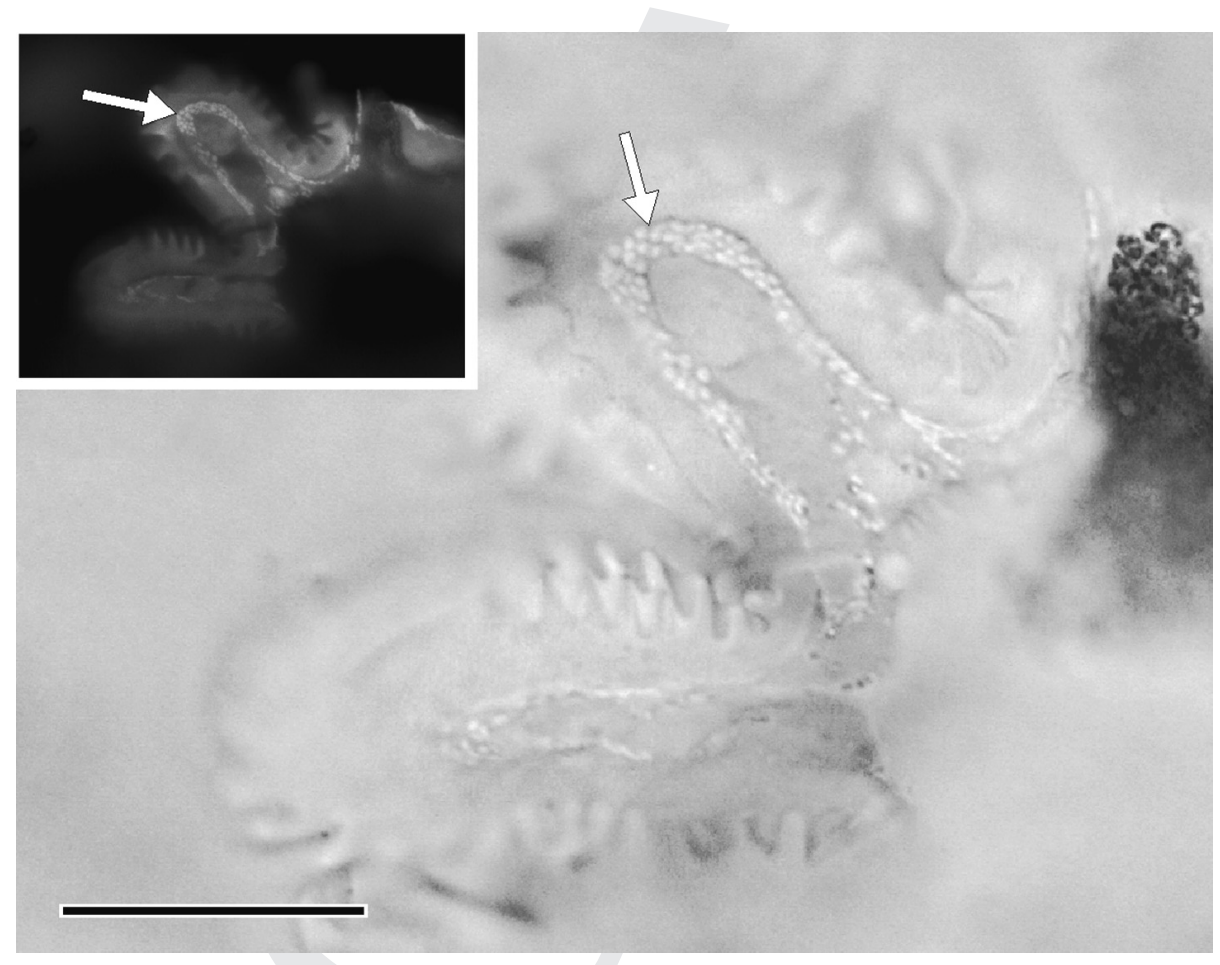

Figure 14.2 Light micrograph of an unstained cross-section of the tegument of the second instar of Misumena vatia. The epithelial cells are full of granules (arrow). The inset shows the same region of tegument observed under UV light. The granules (arrow) show a strong autofluorescence, a characteristic of ommochrome precursors. Scale bar $=15 \mu \mathrm{m}$. See plate section for colour version.

is both exposed for days to direct solar radiation on the top of flowers and has a transparent cuticle exposing the epidermal cells to direct radiation. This transparency implies a need for protective means in the tissues situated beneath the cuticle, and ommochromes might act as such.

To support this conclusion we have analysed the presence of pigment granules in the epidermal cells of the juvenile instars of $M$. vatia. We found that the progranules of pigment precursors (Insausti \& Casas 2008) are already present in the second-instar spiderlings, which have just emerged (Figure 14.2). The spiderlings, when hatched, have a pale whitish-greenish coloration, except on the abdomen, where the brownish intestine and white spots of the crystals of guanine are visible through the translucent cuticle. The yellow coloration was never observed in spiderlings (Gabritschevsky 1927), although the precursors of the ommochrome pigment are present. Thus, they are not some waste products of excessive tryptophan harvested from prey and are needed from birth on.

The comparison with another crab spider, Synaema globosum, reinforces the concept of the role of the ommochrome pigments and their precursors as photoprotectors of the epidermal cells. This species that does not have a camouflage pattern also has a 


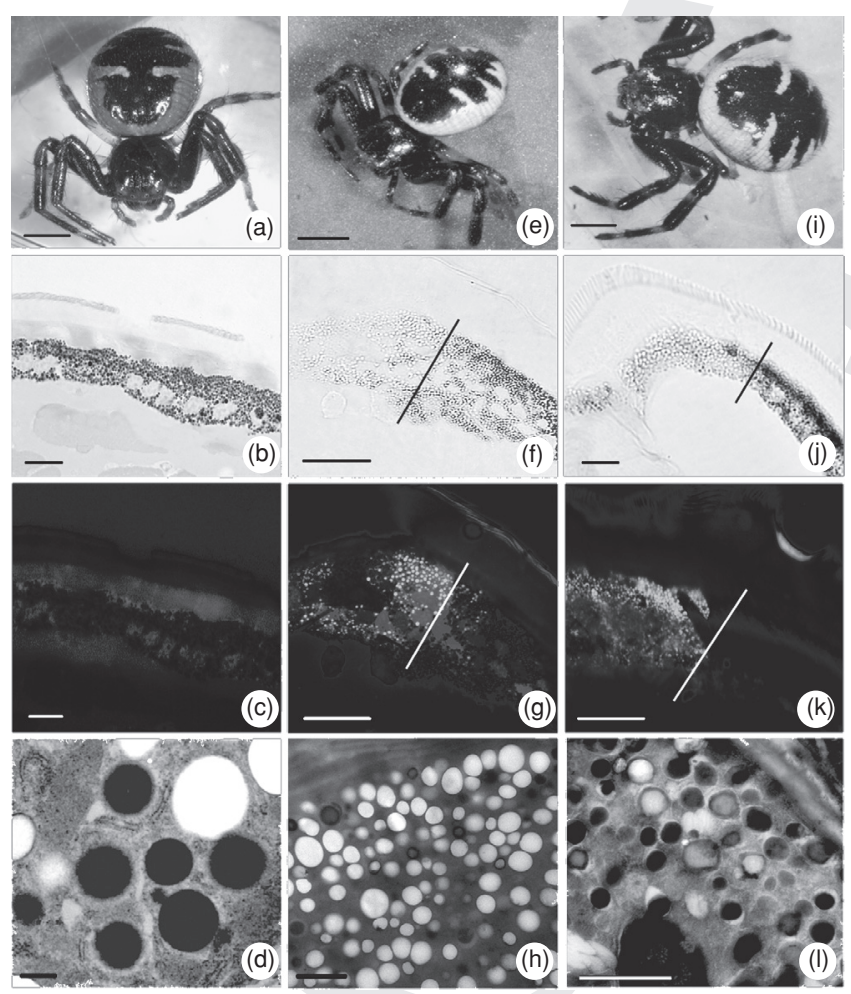

Figure 14.3 Synaema globosum individuals (a-d, e-h and il, respectively) of (a) red, (e) white and (i) yellow colours: (a, e, i) habitus, (b, f, j) unstained cross-sections of the tegument under light microscopy, (c, g, k) under UV light and $(\mathrm{d}, \mathrm{h}, \mathrm{l})$ electron micrographs of epithelial cells and pigment granules. The cuticle of both regions, black and coloured (b), is transparent. The absence of fluorescence in the red spider (c) is typical of ommochromes granules (d). In yellow spiders, there is a distinct difference between the black and yellow areas (on the right and left of the dividing mark), both under light microscopy (j) and under UV light (k). The black region contains two types of granules, red and black, whereas the yellow region contains also two types of granules, translucent and light brown (1). Only the yellow portion contains fluorescent granules. In white spiders, the white region (f) contains translucent, fluorescent granules only $(\mathrm{g}, \mathrm{h})$. As a result, the white coloration is produced by the guanine layer under the epithelium. Almost the totality of the granules is electron-lucent and homogeneous, indicative of kynurenine (granules type I: Insausti \& Casas 2008). There is thus a clear association between body colour and ommochrome metabolites in this non-cryptic crab spider. Scale bars (a, e, i) $=2 \mathrm{~mm}$, $(\mathrm{b}, \mathrm{c}, \mathrm{f}, \mathrm{g}, \mathrm{j}, \mathrm{k})=10 \mu \mathrm{m},(\mathrm{d})=0.5 \mu \mathrm{m}$ and $(\mathrm{h}, \mathrm{l})=2 \mu \mathrm{m}$. See plate section for colour version.

transparent cuticle and comes in three different colour types: white, yellow and red (Figure 14.3). It is unknown whether this spider does change colour or whether these are different fixed phenotypes. Théry \& Casas (2009) observed that both the brown-black and the yellow or red coloured parts of the epidermis contain ommochrome granules, as in M. vatia. The pigmentation of $S$. globosum is therefore another strong hint that the ommochrome coloration might be related to the transparency of the cuticle in crab spiders. Camouflage profits from such a relationship, but may not be the driving force. 
The surprisingly complex relationships between animal colour and background matching described here show how far an assessment of crypsis capacities against the substrates with regard of receiver visual systems provides useful information about how cryptic a given species really is, regardless of any human biases. As shown for this crab spider, a relevant and accurate assessment can be very complex to obtain due to several physiological and ecological constraints. This requires indeed (i) the exact measure of both substrate and individual colorations through spectroradiometric measurements or image analysis in the very location in which the behavioural interaction between prey and predator occurred; (ii) an account of the variability of the substrate visual characteristics encountered by the cryptic species in natural conditions (i.e. the sampling universe); (iii) the identity of the correct receivers; and (iv) a knowledge of their visual abilities. All these reasons explain why accurate measurements of the colour contrast in the perspective of a relevant receiver are so rare. The crab spider $M$. vatia is in these respects one of the best study models, outpacing much more famous examples (Table 14.1). Its potential for addressing fundamental questions in evolutionary physiology and behavioural ecology is not fully realised.

Related puzzling aspects of coloration in spiders are the widespread fluorescence and UV reflectance. The former aspect has being only recently assessed (Andrew et al., 2007; Lim et al., 2007). We doubt that the fluorophores observed by these authors are located in the haemolymph, as stated by Andrews et al. (2007), and rather interpret their results and picture as indicative of a pigment located in the epidermis. Several ommochrome precursors based on the tryptophan pathway located in the epidermis are indeed fluorescent (Insausti \& Casas 2008) and fluorescence might simply be a side effect of the widespread occurrence of ommochromes in spider colours. On the basis of several behavioural tests and ingenious experiments using both native and European bees, it was conclusively demonstrated that UV-reflective body colours of Australian crab spiders attract prey (i.e. bees) to the flowers they are positioned on (Heiling et al., 2003; Heiling \& Herberstein, 2004; Heiling et al., 2005a, b, 2006; Herberstein et al., 2009). While the tropical and subtropical distribution of UV reflectance in crab spiders raises a number of very exciting evolutionary questions about coevolution and trait evolution, the much higher amount of UV radiation received in Australia compared with Europe (Godar 2005) should not be forgotten as an easier potential explanation. Reflectance of UV might act as protective device in tropical and subtropical regions.

\subsection{Spiders mimic ants}

More than 300 species of spiders, belonging to 13 families, mimic ants (Cushing 1997; Nelson \& Jackson 2007). Myrmecomorphic species are defined as spiders mimicking ant morphology and/or behaviour. Morphological adaptations include colour and form modification, which make the spider look as though it has three body segments instead of two, and long slender legs instead of shorter robust legs (review by Cushing 


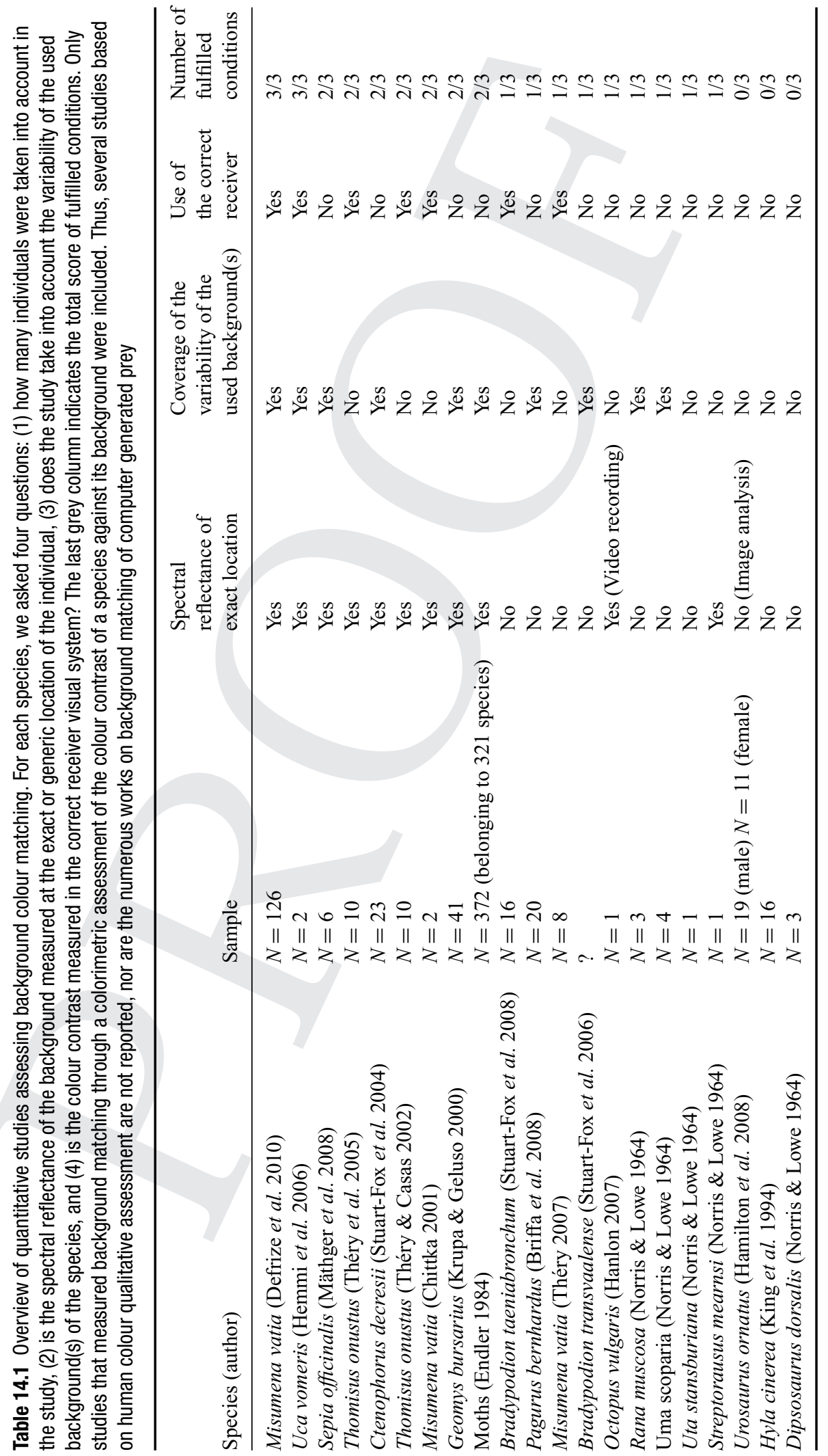


1997). Adaptation of the chelicerae, spinnerets and cuticle coloration allow the spider to mimic the mandibles, sting, compound eyes and antennae of their ant model. Behavioural adaptation includes ant-like erratic movements and the raising of a pair of legs to mimic the movements of ant antennae. Several species of myrmecomorphic spiders evolved transformational mimicry in which successive instars mimic different ant models. Also, several ant-mimicking spiders use polymorphic mimicry in which each morph mimics a different ant morph or species. Some species have each sex mimicking a different ant model. The limited space for this chapter precluded us from doing full justice to movement camouflage that needs more studies in general, as it seems the most striking type of camouflage spiders have used in the course of evolution.

A minority of spider myrmecomorphs are aggressive mimics (McIver \& Stonedahl 1993; Cushing 1997), and use their morphology and behaviour to attract and prey on ant models. A myrmecomorphic spider, Myrmarachne melanotorsa, is also an aggressive mimic but relies on other salticids or on hersilid spiders to mistake them for ants and flee, leaving these araneophagic spiders (Nelson \& Jackson 2009a) access to eggs and postembryos (Nelson \& Jackson 2009b). However, in order for the myrmecomorphic spider to be considered an aggressive mimic by the ant species, the ant model must be a selective agent able to see resemblance of the mimic. This is unlikely for the majority of ant species that have poor eyesight or which do not investigate the spider myrmecomorphs (Cushing 1997). Most myrmecomorphic spiders are considered as Batesian mimics because ant unpalatability offers protection against generalistic arthropod predators. Both direct and indirect evidence support this hypothesis (review in Cushing 1997; Théry \& Casas 2009). Recent experimental studies in the genus Myrmarachne have shown that salticid spider resemblance to ants holds in the eyes of their predators, other salticid species and mantises (Nelson \& Jackson 2006; Nelson et al. 2006a, b). It has also been demonstrated that an ant-mimicking jumping spider is able to discriminate between ant models, conspecifics and prey by sight alone (Nelson \& Jackson 2006, 2007). A recent unpublished study using a physiological model of bird vision has shown that although head and thoracic regions of Myrmarachne gisti are visible to bird predators from a long distance, this myrmecomorphic spider is unlikely to be detected at short distance (D. Li personal communication). By giving the choice between living $M$. gisti and its and model ants under light conditions with and without UV, specialised ant-eating salticids are able to distinguish between ant-mimics and ants based on $M$. gisti's specific display behaviour but not on coloration. These findings provide evidence that this classic ant mimicry has extended into UV light wavelengths, and that Batesian mimicry of $M$. gist $i$ is an effective defence against avian predators.

\subsection{Future prospects}

Spider camouflage and mimicry is attracting attention, mainly from the behavioural ecologist quarter. While we enthusiastically welcome this renewed interest, we caution against glossing over physiological mechanisms. As so often with integrative biology, 


\subsection{Summary}

Diverse functions have been assigned to the visual appearance of webs, spiders and web decorations, including prey attraction, predator deterrence and camouflage. Here, we review the pertinent literature, focussing on potential camouflage and mimicry. Webs are often difficult to detect in a heterogeneous visual environment. Static and dynamic web distortions are used to escape visual detection by prey, although particular silk may also attract prey. Recent work using physiological models of vision taking into account visual environments rarely support the hypothesis of spider camouflage by decorations, but most often the prey attraction and predator confusion hypotheses. Similarly, visual modelling shows that spider coloration is effective in attracting prey but not in conveying camouflage. Camouflage through colour change might be used by particular crab spiders to hide from predator or prey on flowers of different coloration. However, results obtained on a non-cryptic crab spider suggest that an alternative function of pigmentation may be to avoid UV photodamage through the transparent cuticle. Numerous species are clearly efficient locomotory mimics of ants, particularly in the eyes of their predators. We close our chapter by highlighting gaps in our knowledge.

\subsection{Acknowledgements}

We are grateful to Martin Stevens, Sami Merilaita and two anonymous reviewers for their comments that improved the manuscript. 


\section{$14.10 \quad$ References}

Andrew, K., Reed, S. M. \& Masta, S. E. 2007. Spiders fluoresce variably across many taxa. Biology Letters, 3, 265-267.

Bjorkman-Chiswell, B. T., Kulinski, M. M., Muscat, R. L. et al. 2004. Web-building spiders attract prey by storing decaying matter. Naturwissenschaften, 91, 245-248.

Blackledge, T. A. \& Wenzel, J. W. 1999. Do stabilimenta in orb webs attract prey or defend spiders? Behavioral Ecology, 10, 372-376.

Blackledge, T. A. \& Wenzel, J. W. 2000. The evolution of cryptic spider silk: a behavioral test. Behavioral Ecology, 11, 142-145.

Blamires, S. J., Hochuli, D. F. \& Thompson, M. B. 2008. Why cross the web: decoration spectral properties and prey capture in an orb spider (Argiope keyserlingi) web. Biological Journal of the Linnean Society, 94, 221-229.

Brechbühl, R., Casas, J. \& Bacher, S. 2010. Ineffective crypsis in a crab spider: a prey community perspective. Proceedings of the Royal Society, Series B, 277, 739-746.

Briffa, M., Haskell, P. \& Wilding, C. 2008. Behavioural colour change in the hermit crab Pagurus bernhardus: reduced crypticity when the threat of predation is high. Behaviour, 145, 915929.

Bruce, M. J. 2006. Silk decorations: controversy and consensus. Journal of Zoology (London), 269, 89-97.

Bruce, M. J., Herberstein, M. E. \& Elgar, M. A. 2001. Signalling conflict between prey and predator attraction. Journal of Evolutionary Biology, 14, 786-794.

Bruce, M. J., Heiling, A. M. \& Herberstein, M. E. 2005. Spider signals: are web decorations visible to birds and bees? Biology Letters, 1, 299-302.

Bush, A. A., Yu, D. W. \& Herberstein, M. E. 2008. Function of bright coloration in the wasp spider Argiope bruennichi (Araneae: Araneidae). Proceedings of the Royal Society, Series B, 275, 1337-1342.

Cheng, R.-C. \& Tso, I.-M. 2007. Signaling by decorating webs: luring prey or deterring predators? Behavioral Ecology, 18, 1085-1091.

Cheng, R.-C., Yang, E.-C., Lin, C.-P., Herberstein, M. E. \& Tso, I.-M. 2010. Insect form vision as one potential shaping force of spider web decoration design. Journal of Experimental Biology, 213, 759-768.

Chiao, C. C., Wu, W. Y., Chen, S. H. \& Yang, E. C. 2009. Visualization of the spatial and spectral signals of orb-weaving spiders, Nephila pilipes, through the eyes of a honeybee. Journal of Experimental Biology, 212, 2269-2278.

Chittka, L. 2001. Camouflage of predatory crab spiders on flowers and the colour perception of bees (Aranida: Thomisidae/Hymenoptera: Apidae). Entomologia Generalis, 25, 181-187.

Chou, I.-C., Wang, P.-H., Shen, P.-S. \& Tso, I.-M. 2005. A test of prey-attracting and predator defence functions of prey carcass decorations built by Cyclosa spiders. Animal Behaviour, 69, $1055-1061$.

Chuang, C.-Y., Yang, E.-C. \& Tso, I.-M. 2007. Diurnal and nocturnal prey luring of a colorful predator. Journal of Experimental Biology, 210, 3830-3837.

Chuang, C.-Y., Yang, E.-C. \& Tso, I.-M. 2008. Deceptive color signaling in the night: a nocturnal predator attracts prey with visual lures. Behavioral Ecology, 19, 237-244.

Craig, C. L. 1986. Orb-web visibility: the influence of insect flight behaviour and visual physiology on the evolution of web designs within the Araneoidea. Animal Behaviour, 34, 54-68. 
Craig, C. L. 1988. Insect perception of spider webs in three light environments. Functional Ecology, 2, 277-282.

Craig, C. L. 1990. Effects of background pattern on insect perception of webs spun by orb-weaving spiders. Animal Behaviour, 39, 135-144.

Craig, C. L. \& Bernard, G. D. 1990. Insect attraction to ultraviolet-reflecting spider webs and web decorations. Ecology, 71, 616-623.

Craig, C. L. \& Freeman, C. R. 1991. Effects of predator visibility on prey encounter: a case study on aerial web weaving spiders. Behavioral Ecology and Sociobiology, 29, 249254.

Craig, C. L., Weber, R. S. \& Bernard, G. D. 1996. Evolution of predator-prey systems: spider foraging plasticity in response to the visual ecology of prey. American Naturalist, 147, 205229.

Cushing, P. E. 1997. Myrmecomorphy and myrmecophily in spiders: a review. Florida Entomologist, 80, 165-193.

Defrize, J., Théry, M. \& Casas, J. 2010. Background colour matching by a crab spider in the field: a community sensory ecology perspective. Journal of Experimental Biology, 213, 14251435.

Dontsov, A. E. 1999. Comparative study of spectral and antioxidant properties of pigments from the eyes of two Mysis relicta (Crustacea, Mysidacea) populations, with different light damage resistence. Journal of Comparative Physiology B, 169, 157-164.

Dontsov, A. E., Lapina, V. A. \& Ostrovsky, M. A. 1984. Photoregeneration of $\mathrm{O}_{2}$ by ommochromes and their role in the system of antioxidative protection of invertebrate eye cells. Biofizika, 29, 878-882.

Eberhard, W. G. 2003. Substitution of silk stabilimenta for egg sacs by Allocyclosa bifurca (Araneae: Araneidae) suggests that silk stabilimenta function as camouflage devices. Behaviour, 140, $847-868$.

Eisner, T. \& Nowicki, S. 1983. Spider-web protection through visual advertisment: role of the stabilimentum. Science, 219, 185-187.

Elgar, M. A., Allan, R. A. \& Evans, T. A. 1996. Foraging strategies in orb-spinning spiders: ambient light and silk decorations in Argiope aetherea Walckenaer (Araneae: Araneoidea). Austral Ecology, 21, 464-467.

Endler, J. A. 1984. Progressive background in moths, and a quantitative measure of crypsis. Biological Journal of the Linnean Society, 22, 187-231.

Fan, C. M., Yang, E. C. \& Tso, I. M. 2009. Hunting efficiency and predation risk shapes the color-associated foraging traits of a predator. Behavioral Ecology, 20, 808-816.

Fuzeau-Braesch, S. 1985. Colour changes. In Comprehensive Insect Physiology, Biochemistry and Pharmacology, eds. Kerkut, G. A. \& Gilbert, L. I. Oxford, UK: Pergamon Press, pp. 549589.

Gabritschevsky, E. 1927. Experiments on color changes and regeneration in the crab-spider, Misumena vatia. Journal of Experimental Zoology, 47, 251-267.

Gawryszewski, F. M. \& Motta, P. C. 2008. The silk tuft web decorations of the orb-weaver Gasteracantha cancriformis: testing the prey attraction and the web advertisement hypotheses. Behaviour, 145, 277-295.

Godar, D. E. 2005. UV doses worldwide. Photochemistry and Photobiology, 81, 736-749.

Gonzaga, M. O. \& Vasconcellos-Neto, J. 2005. Testing the functions of detritus stabilimenta in webs of Cyclosa fililineata and Cyclosa morretes (Araneae: Araneidae): do they attract prey or reduce the risk of predation? Ethology, 111, 479-491. 
Hamilton, P. S., Gaalema, D. E. \& Sullivan, B. K. 2008. Short-term changes in dorsal reflectance for background matching in Ornate Tree Lizards (Urosaurus ornatus). Amphibia-Reptilia, 29, 473-477.

Hanlon, R. 2007. Cephalopod dynamic camouflage. Current Biology, 17, 400-404.

Heckel, E. 1891. Sur le mimétisme de Thomisus onustus. Bulletin Scientifique de la France et de la Belgique, 23, 347-354.

Heiling, A. M. \& Herberstein, M. E. 2004. Predator-prey coevolution: Australian native bees avoid their spider predators. Proceedings of the Royal Society, Series B, 271 (Suppl.), S196S198.

Heiling, A. M., Herberstein, M. E. \& Chittka, L. 2003. Crab-spiders manipulate flower signals. Nature, 421, 334.

Heiling, A. M., Cheng, K., Chittka, L., Goeth, A. \& Herberstein, M. E. 2005a. The role of UV in crab spider signals: effects on perception by prey and predators. Journal of Experimental Biology, 208, 3925-3931.

Heiling, A. M., Chittka, L., Cheng, K. \& Herberstein, M. E. 2005b. Colouration in crab spiders: substrate choice and prey attraction. Journal of Experimental Biology, 208, 1785-1792.

Heiling, A. M., Cheng, K. \& Herberstein, M. E. 2006. Picking the right spot: crab spiders position themselves on flowers to maximize prey attraction. Behaviour, 143, 957-968.

Hemmi, J. H., Marshall, J., Pix, W., Vorobyev, M. \& Zeil, J. 2006. The variable colours of the fiddler crab Uca vomeris and their relation to background and predation. Journal of Experimental Biology, 209, 4140-4153.

Herberstein, M. E. \& Fleisch, A. F. 2003. Effect of abiotic factors on the foraging strategy of the orb-web spider Argiope keyserlingi (Araneae: Araneidae). Austral Ecology, 28, 622-628.

Herberstein, M. E., Craig, C. L., Coddington, J. A. \& Elgar, M. A. 2000. The functional significance of silk decorations of orb-web spiders: a critical review of the empirical evidence. Biological Reviews, 75, 649-669.

Herberstein, M. A., Heiling, A. M. \& Cheng, K. 2009. Evidence for UV-based sensory exploitation in Australian but not European crab spiders. Evolutionary Ecology, 23, 621-634.

Insausti, T. C. \& Casas, J. 2008. The functional morphology of color changing in a spider: development of ommochrome pigment granules. Journal of Experimental Biology, 211, 780 789.

Insausti, T. C. \& Casas, J. 2009. Turnover of pigment granules: cyclic catabolism and anabolism within epidermal cells. Tissue and Cell, 41, 421-429.

Kayser, H. 1985. Pigments. In Comprehensive Insect Physiology, Biochemistry and Pharmacology, eds. Kerkut, G. A. \& Gilbert, L. I. Oxford, UK: Pergamon Press, pp. 367-415.

King, R. B., Hauff, S. \& Phillips, J. B. 1994. Physiological color change in the green treefrog: responses to background brightness and temperature. Copeia, 2, 422-432.

Krupa, J. K. \& Geluso, K. N. 2000. Matching the color of excavated soil: cryptic coloration in the plains pocket gopher (Geomys bursarius). Journal of Mammalogy, 81, 86-96.

Langer, H. 1975. Properties and functions of screening pigments in insects eyes. In Photoreceptor Optics, eds. Snyder, A. W. \& Menzel, R. Berlin: Springer, pp. 429-455.

Li, D. 2005. Spiders that decorate their webs at higher frequency intercept more prey and grow faster. Proceedings of the Royal Society, Series B, 272, 1753-1757.

Li, D., Lim, M. L. M., Seah, W. K. \& Tay, S. L. 2004. Prey attraction as a possible function of discoid stabilimenta of juvenile orb-spinning spiders. Animal Behaviour, 68, 629-635.

Lim, M. L. M., Land, M. F. \& Li, D. 2007. Sex-specific UV and fluorescence signals in jumping spiders. Science, $\mathbf{3 1 5}, 481$. 
Linzen, B. 1974. The tryptophan $\rightarrow$ ommochrome pathway in insects. In Advances in Insect Physiology, eds. Treherne, J. E., Berridge, M. J. \& Wigglesworth, V. B. London: Academic Press, pp. 117-246.

Mackenzie, S. M., Howells, A. J., Cox, G. B. \& Ewart, G. D. 2000. Sub-cellular localisation of the White/Scarlet ABC transporter to pigment granule membranes within the compound eye of Drosophila melanogaster. Genetica, 108, 239-252.

Mäthger, L. M., Chiao, C. C., Barbosa, A. \& Hanlon, R. T. 2008. Color matching on natural substrates in cuttlefish, Sepia officinalis. Journal of Comparative Physiology A, 194, 577585.

McIver, J. D. \& Stonedahl, G. 1993. Myrmecomorphy: morphological and behavioral mimicry of ants. Annual Review of Entomology, 38, 351-379.

Millot, J. 1926. Contributions à l'histophysiologie des araneides. Bulletin Biologique de la France et de la Belgique, 8 (Suppl.), 1-283.

Morse, D. H. 2007. Predator upon a Flower: Life History and Fitness in a Crab Spider. Cambridge, MA: Harvard University Press.

Nakata, K. 2008. Spiders use airborne cues to respond to flying insect predators by building orb-web with fewer silk thread and larger silk decorations. Ethology, 114, 686-692.

Nakata, K. 2009. To be or not to be conspicuous: the effects of prey availability and predator risk on spider's web decoration building. Animal Behaviour, 78, 1255-1260.

Needham, A. E. 1974. The Significance of Zoochromes. Berlin: Springer.

Nelson, X. J. \& Jackson, R. R. 2006. Vision-based innate aversion to ants and ant mimics. Behavioral Ecology, 17, 676-681.

Nelson, X. J. \& Jackson, R. R. 2007. Vision-based ability of an ant-mimicking jumping spider to discriminate between models, conspecific individuals and prey. Insectes Sociaux, 54, $1-4$.

Nelson, X. J. \& Jackson, R. R. 2009a. Prey classification by an araneophagic ant-like jumping spider (Araneae: Salticidae). Journal of Zoology, 279, 173-179.

Nelson, X. J. \& Jackson, R. R. 2009b. Aggressive use of Batesian mimicry by an ant-like jumping spider. Biology Letters, 5, 755-757.

Nelson, X. J., Jackson, R. R., Li, D., Barrion, A. T. \& Edwards, G. B. 2006a. Innate aversion to ants (Hymenoptera: Formicidae) and ant mimics: experimental findings from mantises (Mantodea). Biological Journal of the Linnean Society, 88, 23-32.

Nelson, X. J., Li, D. \& Jackson, R. R. 2006b. Out of the frying pan and into the fire: a novel trade-off for Batesian mimics. Ethology, 112, 270-277.

Norris, K. S. \& Lowe, C. H. 1964. An analysis of background color-matching in amphibians and reptiles. Ecology, 45, 565-580.

Ostrovsky, M. A. \& Fedorovich, I. B. 1994. Retinal as sensitizer of photodamage to retinal proteins of eye retina. Biofisika, 39, 13-25.

Ostrovsky, M. A., Sakina, N. L. \& Dontsov, A. E. 1987. An antioxidative role of ocular screening pigments. Vision Research, 27, 893-899.

Oxford, G. S. 2005. Genetic drift within a protected polymorphism: enigmatic variation in color-polymorph frequencies in the candy-stripe spider, Enoplognatha ovata. Evolution, 59, 2170-2184.

Oxford, G. S. \& Gillespie, R. G. 1998. Evolution and ecology of spider coloration. Annual Review of Entomology, 43, 619-643.

Oxford, G. S. \& Gillespie, R. G. 2001. Portraits of evolution: studies of coloration in Hawaiian spiders. BioSciences, 51, 521-528. 
Rao, D., Webster, M., Heiling, A. M., Bruce, M. J. \& Herberstein, M. E. 2009. The aggregating behaviour of Argiope radon, with special reference to web decorations. Journal of Ethology, 27, 35-42.

Sakina, N. L., Dontsov, A. E., Lapina, V. A. \& Ostrovsky, M. A. 1987. Protective system of eye structures from photoinjury. II. Screening pigments of arthropods - ommochromes - as inhibitors of photooxidative processes. Journal of Evolutionary Biochemistry and Physiology, 23, 702-706.

Seah, W. K. \& Li, D. 2001. Stabilimenta attract unwelcome predators to orb-webs. Proceedings of the Royal Society, Series B, 268, 1553-1558.

Seligy, V. L. 1972. Ommochrome pigments of spiders. Comparative Biochemistry and Physiology $A, \mathbf{4 2}, 699-709$.

Starks, P. T. 2002. The adaptive significance of stabilimentum in orb-webs: a hierarchical approach. Annales Zoologici Fennici, 39, 307-315.

Stavenga, D. G. 1989. Pigments in compound eyes. In Facets of Vision, eds Stavenga, D. G. \& Hardie, R. C. Berlin: Springer, pp. 152-172.

Stuart-Fox, D., Moussalli, A., Johnston, G. R. \& Owens, I. P. F. 2004. Evolution of color variation in dragon lizards: quantitative tests of the role of crypsis and local adaptation. Evolution, 58, 1549-1559.

Stuart-Fox, D., Moussalli, A. \& Whiting, M. J. 2008. Predator-specific camouflage in chameleons. Biology Letters, 4, 326-329.

Stuart-Fox, D., Whiting, M. J. \& Moussalli, A. 2006. Camouflage and colour change: antipredator responses to bird and snake predators across multiple populations in a dwarf chameleon. Biological Journal of the Linnean Society, 88, 437-466.

Tan, E. J. \& Li, D. Q. 2009. Detritus decorations of an orb-weaving spider, Cyclosa mulmeinensis (Thorell): for food or camouflage? Journal of Experimental Biology, 212, 1832-1839.

Tan, E. J., Stanley, W. H. S., Yap, L. et al. 2010. Why do orb-weaving spiders (Cyclosa ginnaga) decorate their webs with silk spirals and plant detritus? Animal Behaviour, 79, 179-186.

Théry, M. 2007. Colours of background reflected light and of the prey's eye affect adaptive coloration in female crab spiders. Animal Behaviour, 73, 797-804.

Théry, M. \& Casas, J. 2002. Predator and prey views of spider camouflage. Nature, 415, 133.

Théry, M. \& Casas, J. 2009. The multiple disguises of spiders: web colour and decorations, body colour and movement. Philosophical Transactions of the Royal Society, Series B, 364, 471480 .

Théry, M., Debut, M., Gomez, D. \& Casas, J. 2005. Specific color sensitivities of prey and predator explain camouflage in different visual systems. Behavioral Ecology, 16, 25-29.

Tietjen, W. J., Ayyagari, L. R. \& Uetz, G. W. 1987. Symbiosis between social spiders and yeast: the role in prey attraction. Psyche, 94, 151-158.

Tseng, L. \& Tso, I. M. 2009. A risky defence by a spider using conspicuous decoys resembling itself in appearance. Animal Behaviour, 78, 425-431.

Tso, I. M. 1998. Isolated spider web stabilimentum attracts insects. Behaviour, 135, 311-319.

Tso, I.-M., Liao, C.-P., Huang, R.-P. \& Yang, E.-C. 2006. Function of being colorful in web spiders: attracting prey or camouflaging oneself? Behavioral Ecology, 17, 606-613.

Tso, I.-M., Huang, J.-P. \& Liao C.-P. 2007. Nocturnal hunting of a brightly coloured sit-and-wait predator. Animal Behaviour, 74, 787-793.

Vanderhoff, E. N., Byers, C. J. \& Hanna, C. J. 2008. Do the color and pattern of Micrathena gracilis (Araneae : Araneidae) attract prey? Examination of the prey attraction hypothesis and crypsis. Journal of Insect Behavior, 21, 469-475. 
Vuillaume, M. 1968. Pigmentations et variations pigmentaires de trois insectes: Mantis religiosa, Sphodromantis viridis, et Locusta migratoria. Bulletin Biologique de la France et de la Belgique, 102, 147-232.

Walter, A., Elgar, M. A., Bliss, P. \& Moritz, R. F. A. 2008. Wrap attack activates web-decorating behavior in Argiope spiders. Behavioral Ecology, 19, 799-804.

Walter, A., Bliss, P., Elgar, M. A. \& Moritz, R. F. A. 2009. Argiope bruennichi shows a drinking-like behaviour in web hub decorations (Araneae, Araneidae). Journal of Ethology, 27, $25-29$. 